\title{
Psychosocial Stressors and Salivary Cortisol Levels in A Sample of Healthy Young Adults
}

\author{
Sahar M. Greish \\ Department of Physiology, Faculty of Medicine, Suez Canal University, Egypt
}

\begin{abstract}
Background: Stress has increasingly become a major concern for public health. It is known that psychological stress could produce physiological effects resembling physical challenges in a variety of physiological systems. Salivary cortisol reliably reflects the hypothalamus-pituitaryadrenocortical axis (HPA) activity. Aim: to describe the risks with constant exposure to stress and to determine its association with salivary cortisol. Patients and Methods: Cross-sectional study of 81 resident physicians working in Suez Canal University Hospital. Occupational psychosocial risk and perceived stress level were assessed with validated version of the Copenhagen Psychosocial Questionnaire (COPSOQ). Salivary cortisol was also measured as a biochemical marker of stress in the morning and evening. Results: The physicians reported psychosocial risk factors, particularly high demand on psychological resources and low job control. Cortisol levels were within the normal range. On bivariate analysis, no associations were found between COPSOQ findings and cortisol levels. Conclusions: Resident physicians are in a potentially harmful working situation, although we detected no effect on cortisol level as a biochemical marker of stress.
\end{abstract}

Keywords: Stress, Salivary Cortisol, Copenhagen Psychosocial Questionnaire (COPSOQ)

\section{Introduction}

It is widely accepted that psychological stress could produce physiological effects that are similar to those produced by physical challenges in a variety of physiological systems. Two primary systems are particularly involved in setting on the stress response, hypothalamus/ pituitary/ adrenocortical axis (HPA) and sympatho-adrenomedullary (SAM) system. The activation of HPA causes an increase in cortisol secretion in adrenal cortex ${ }^{(1,2)}$. Salivary cortisol concentrations are closely correlated to serum cortisol. Thus, it reliably reflects the HPA activity, and is a more practical assessment tool than blood collection in stress research due to its potential to elicit spurious increases in cortisol secretion reflecting a hyper-stress component. Many reports have shown that various kinds of psychological stress activate the HPA of cortisol release, and consequently, induce significant increases in salivary cortisol level above the resting baseline level ${ }^{(3)}$. Stress has increasingly become a major concern for public health. In this regard, it is a wellrecognized problem among health workers, affecting physicians in general and especially those who work in the emergency critical situations ${ }^{(4)}$. Stress is a functional response, which allows the organism to adapt to physical situations or psychological demands. Stress appears when the individual does not have, or believes he does not have, the skills required to meet a situation, and cannot therefore meet his/her professional demands ${ }^{(4)}$. Thus, high and 
sustained levels of stress contribute to the etiology of many diseases, such as cardiovascular disease ${ }^{(5)}$, or increased incidence of viral infection ${ }^{(6-8)}$. Stress can also increase psychiatric co-morbidity among medical staff $^{(9)}$. A situation perceived as stressful triggers a series of mechanisms among which is the activation of the hypothalamo-hypophyseal-adrenal axis, one of whose end products is cortisol. This biochemical marker is particularly sensitive to chronic stress ${ }^{(10)}$. Numerous studies have focused on analyzing and correlating stress and physiological indicators of stress $^{(11,12)}$. However, we understand that this dyad is necessary but not sufficient to evaluate it. Besides these, one should also analyze the psychosocial risks associated with the job ${ }^{(13)}$, and whether these intrinsically predispose the worker to suffer high levels of stress. Medical staff works under high pressure, because of the unpredictability of demand and the need to respond rapidly to situations. Moreover, their activity is conditioned with misuse of Medical staff by the general population and current budgetary constraints ${ }^{(14,15)}$. Therefore, medical staff is considered at risk of high levels of stress. The aim of this study was to describe the risks with constant exposure to stress and to determine salivary cortisol levels in a sample of medical staff, and explore the association, between these two variables.

\section{Subjects and Methods}

\section{Subjects}

An analytical cross-sectional study was conducted between July 2014 and September 2014 in the Suez Canal University Hospital. The participants were 81 resident physicians ( 37 females and 44 males), with at least 3 month of work duration. To avoid the effects of potential confounding factors that may affect either exposure or outcome variables, physicians who had any of the following criteria were excluded from the study: 1) Diabetes, Hypertension, Migraine or taking regular medications, 2) Any surgical operations during last month, 3) Loss of any family member during the last month, 4) smokers or alcoholics, 5) Pregnancy and during perimentstrual changes.

\section{Methods}

Each participant was given instructions on how to complete the questionnaires, along with a sheet of instructions. A written consent form was taken from each participant as mandated by the Research Ethics Board [REB] of the Faculty of Medicine, Suez Canal University in accordance with Helsinki declaration.

\section{Assessment of psychosocial stressors}

The questionnaire for assessment of psychosocial stressors is based on items of (COPSOQ) $)^{(16)}$. It is designed to identify measure and assess exposure to six large dimensions of psychosocial risks, namely: 1 ) Psychological demands (workload in relation to time available to perform it and transfer of feelings at work). 2) Dual role (need to respond simultaneously to the demands of professional work and domestic work and family). 3) Job control (range of autonomy in how to perform the work and the possibilities of applying skills and knowledge). 4) Social support and quality of leadership (support from superiors or colleagues at the performance of work). 5) Esteem (staff recognition and respect obtained in relation to the effort made at work). 6) Uncertainty about the future (concern about changes in working conditions or job loss). These levels of exposure were classified qualitatively as unfavorable, intermediate, or favorable. This criterion referred to the psychosocial risk that has its origin in the organization of the work.

\section{Measurement of cortisol level}

Salivary Cortisol was measured in the morn- 
ing (30 minutes after waking up) and in the evening (at the end of workday) ${ }^{(17)}$. Quantitative determination of Cortisol was done by enzyme immunoassay principle. Samples were collected and stored at $-4^{\circ} \mathrm{C}$ for up to 24 hours then stored at $-20^{\circ} \mathrm{C}$ until analysis. Cortisol in saliva was measured using the commercial kit Imunospec ${ }^{\circledR}$ according to the manufacturer's instructions (Immunospec Corporation USA) Catalog No. E18-188. Reference values for cortisol in saliva were provided by the manufacturer.

\section{Statistical analysis}

Statistical analysis was performed using SPSS 16.0 and Microsoft Excel 2007. Differences with a $p$ value less than 0.05 were considered statistically significant.

\section{Results}

\section{Dimensions of exposure to stress}

The scores of the dimensions that make up the questionnaire and exposure levels corresponding to mean scores on each dimension were presented in table (1). Unfavorable exposure was observed in almost all dimensions (Psychological demands, Dual role, Social support and leadership Esteem). Unfavorable psychological demands (values between 12 and 24). Unfavorable dual role (values between 7 and 16). Intermediate control over work (values between 19 and 25). Unfavorable social support (values between 0 and 24). Unfavorable esteem (values between 0 and 9).

Table 1: Scores of each dimension and its level of exposure

\begin{tabular}{|l|ll|}
\hline & Mean \pm SD & Level of exposure \\
\hline - Psychological demands & $15.5 \pm 3.3$ & Unfavorable \\
- Dual role & $8.7 \pm 3.3$ & Unfavorable \\
- Control over work & $21.5 \pm 5.6$ & Intermediate \\
- Social support and leadership & $22.4 \pm 6.3$ & Unfavorable \\
- Esteem & $7.4 \pm 2.9$ & Unfavorable \\
- Insecurity of the future & $8.3 \pm 2.9$ & Intermediate \\
\hline
\end{tabular}

Table 2: The level of exposure to each dimension according to gender

\begin{tabular}{|l|ccc|ccc|ccc|}
\hline & \multicolumn{3}{|c|}{ Unfavorable } & \multicolumn{3}{c|}{ Intermediate } & \multicolumn{3}{c|}{ Favorable } \\
\cline { 2 - 11 } & Males & Females & $T$ & Males & Females & $T$ & Males & Females & $T$ \\
\hline - Psychological demands & 22 & 26 & 48 & 11 & 7 & 18 & 9 & 6 & 15 \\
- Dual role & 15 & 26 & 41 & 18 & 8 & 26 & 8 & 6 & 14 \\
- Control over work & 13 & 14 & 27 & 16 & 15 & 31 & 13 & 10 & 23 \\
- Social support \& lead- & 19 & 12 & 31 & 14 & 11 & 25 & 9 & 16 & 25 \\
ership & & & & & & & & & \\
- Esteem & 19 & 25 & 44 & 13 & 10 & 23 & 8 & 6 & 14 \\
- Insecurity of the future & 11 & 10 & 21 & 15 & 13 & 28 & 16 & 16 & 32 \\
Total & 99 & 113 & & 87 & 64 & & 63 & 60 & \\
\hline
\end{tabular}

Intermediate insecurity (values between 5 and 9). The response to each dimension of the questionnaire items by the level of unfavorable, intermediate, or favorable exposure, according to gender is demonstrated in Table 2. There is high number of medical staff who scored unfavorably on all dimen- sions, with the exception of uncertainty about the future. In addition, when classified by gender, it was found more negative results for females in the dimensions of psychological demands, dual role and esteem, but only dual role was significant ( $p$ less than 0.003). 
Table 3: The serum levels of salivary cortisol in the morning and evening

\begin{tabular}{|c|ccc|}
\hline $\begin{array}{c}\text { Cortisol Levels } \\
(\mathrm{ng} / \mathrm{ml})\end{array}$ & $\begin{array}{c}\text { Females } \\
(\mathrm{n}=81)\end{array}$ & $\begin{array}{c}\text { Males } \\
(\mathrm{n}=81)\end{array}$ & p-value \\
\hline Morning level & $26.73 \pm 4.72$ & $28.58 \pm 4.65$ & 0.078 \\
Evening level & $20.18 \pm 4.17$ & $21.27 \pm 3.04$ & 0.181 \\
\hline
\end{tabular}

Data are presented as mean \pm SD

Cortisol level in the study population

Table 3 shows the serum levels of salivary cortisol. There was no statistically significant difference between serum levels and the gender of studied medical staff. In addition, all the values are in the normal range. It was found that there is no significant association between the questionnaire scores (in all the six dimensions) and the level of salivary cortisol in the morning regards to the female physician $(r=0.108$, $p=0.52)$. Although, there is a significant association between the questionnaire scores and the level of salivary cortisol in the morning regards to the male physician $(r=0.306, p=0.04)$. In addition, it was found that there is no significant association between the questionnaire scores and the level of salivary cortisol at evening in both female and male physician $(r=0.162,0.165$ for male and female respectively), figures 1 and 2.

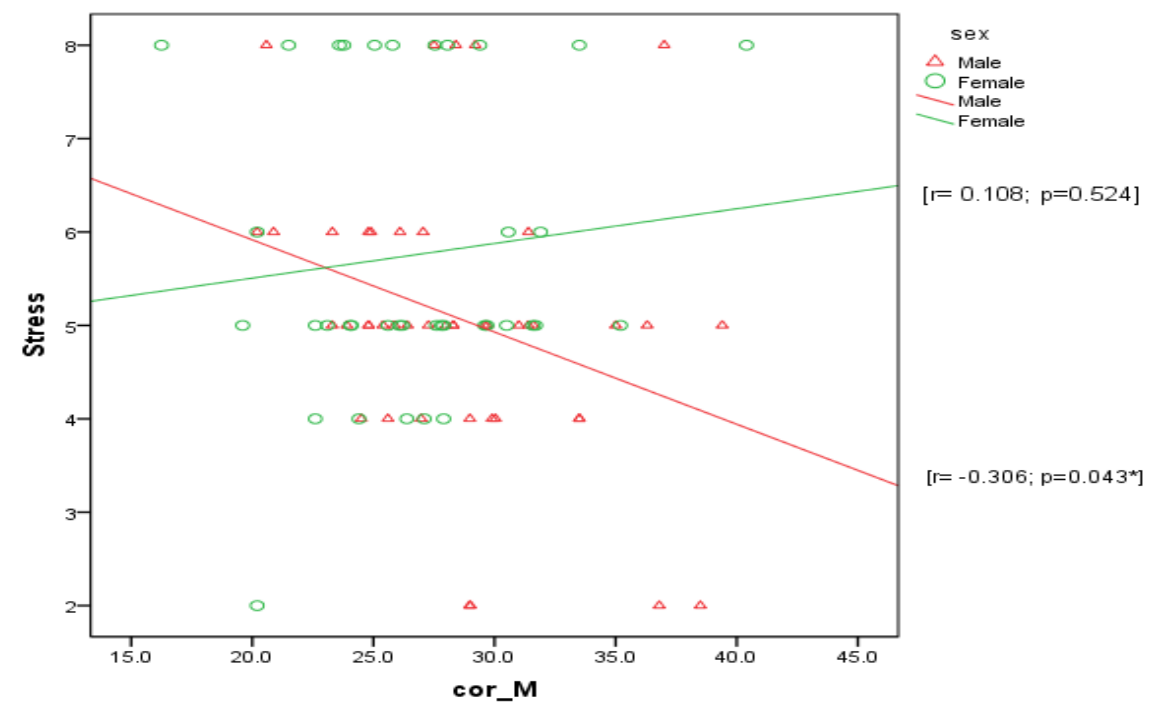

Figures 1: Correlation between the total score of stress and the serum levels of salivary cortisol (in the morning)

\section{Discussion}

The present study dealt with stress in medical staff using questionnaires and measurement of cortisol in saliva as a physiological indicator for stress. According to the data obtained from this study, the sample experienced high psychological demands, intermediate job control (although nearly $35 \%$ scored this dimension unfavorably) and unfavorable social support. In a previous model of psychological demands-control, physicians were classified in the active quadrant (high demands and high control $)^{(18)}$, however, our data indicated that our physicians were classified within the quadrant of "high tension" (high demands and low control). As proposed in another study ${ }^{(19)}$, this could generate an increase in 
self-perceived stress and/or burnout.

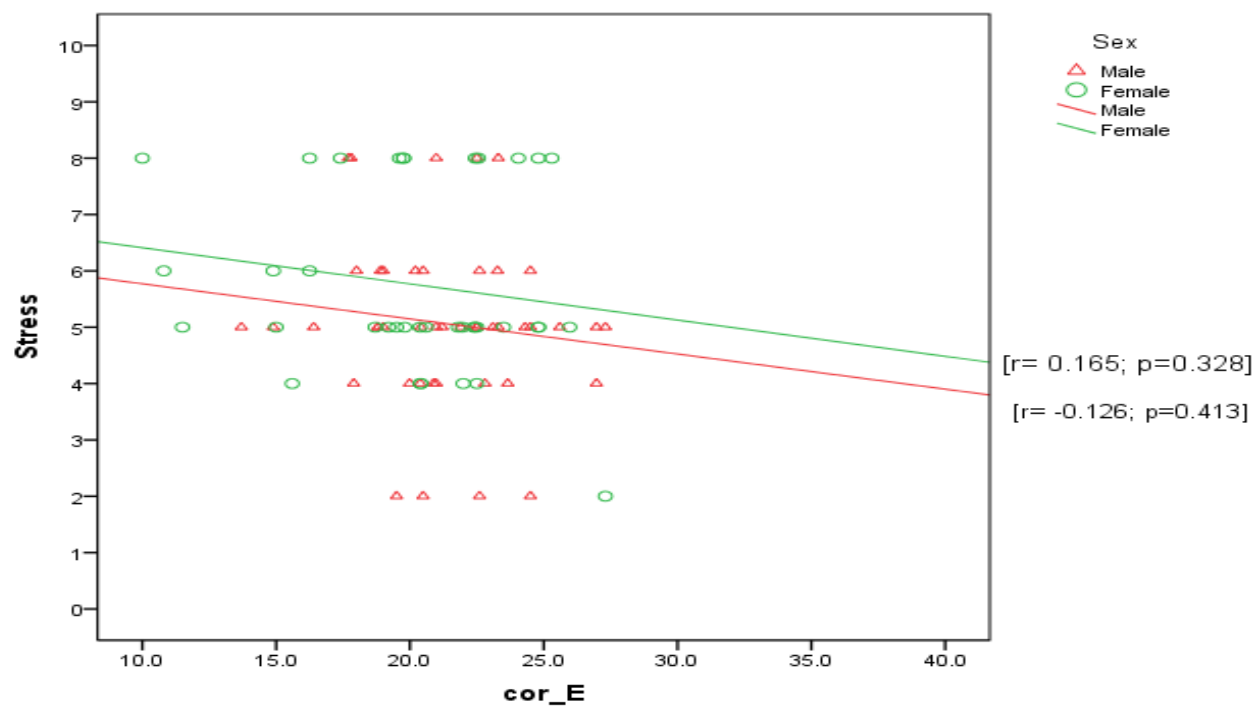

Figures 2: Correlation between the total score of stress and the serum levels of salivary cortisol (in the evening)

The existence of significant correlations between social support and most of the remaining dimensions reinforces the model of interaction between demands, control and social support ${ }^{(20)}$, and the importance of this dimension in the work context as a modulator of stress. Furthermore, the dual role dimension confirmed the pressure that women face to respond simultaneously to the demands of the job and domestic work and family, which is reported in another study ${ }^{(16)}$. The results concerning perceived stress were generally unfavorable. The male medical staff had the highest scores for self-perceived stress and the highest values of salivary cortisol. Compared to other studies to date, our results also showed no relationship between the psychological and physiological parameters of stress $^{(21-23)}$. However, there were data that show relationships between cortisol and subjective variables ${ }^{(24)}$. There should be a clarification that there is also empirical evidence of a negative relationship between measures of stress and salivary cortisol ${ }^{(25)}$. However, almost all the previous studies ${ }^{21-}$ 29), used other validated questionnaires whose points system were not validated for the Arab population and this could explain in part the lack of association between psychological and physiological parameters. The results showed no change in cortisol levels that may be associated with stress or psychosocial risk in the workplace, at least not with the questionnaires used in this research. This could be interpreted as physiological adaptation to the job and its demands, which could be responsible for normalization of physiological stress. However, at the psychological level, this did not seem to occur. The present study had a limitation that we could have used other questionnaires administered in Arabic studies to establish convergence and validity.

\section{Conclusions}

Physicians are in a potentially harmful working situation, although we detected no effect on salivary cortisol as a biochemical marker of stress.

\section{References}

1. Sapolsky RM, Krey LC, McEwen BS. The 
neuroendocrinology of stress and aging: the glucocorticoid cascade hypothesis. Endocrinol Rev 1986;7 (3): 284-301.

2. Al' Absi M, Arnett DK. Adrenocortical responses to psychological stress and risk for hypertension. Biomed Pharmacother 2000;54 (5): 234-44.

3. Kirschbaum C, Hellhammer DH. Salivary cortisol in psychoneuroendocrine research: recent developments and applications. Psychoneuroendocrinology 1994;19 (4): 313-333.

4. González J, Fernández M, Molina R, Blázquez A, Guillén J, María J. Psychosocial risk at work, self-perceived stress, and salivary cortisol level in a sample of emergency physicians in Granada. Emergencias 2012; 24: 101-106

5. Blackmore ER1, Stansfeld SA, Weller I, Munce S, Zagorski BM, Stewart DE. Major Depressive Episodes and Work Stress: Results from a National population survey. Am J Public Health. 2007;97 (11):20882093.

6. Bauer ME, Vedhara K, Perks P, Wilcock GK, Lightman SL, Shanks N. Chronic stress in caregivers of dementia patients is associated with reduced lymphocyte sensitivity to glucocorticoids. J Neuroimmunol. 2000; 103 (1):84-92.

7. Esterling BA, Kiecolt-Glaser JK, Bodnar JC, Glaser R. Chronic stress, social support, and persistent alterations in the natural killer cell response to cytokines in older adults. Health Psychol. 1994;13 (4):291298.

8. Vedhara K, Cox NK, Wilcock GK, Perks P, Hunt $M$, Anderson S, Lightman SL, Shanks NM. Chronic stress in elderly carers of dementia patients and antibody response to influenza vaccination. Lancet. 1999;353 (9153):627- 631.

9. Burbeck R, Coomber S, Robinson SM, Todd C. Occupational stress in consultants in accident and emergency medicine: a national survey of levels of stress at work. Emerg Med J. 2002;19 (3):234-238.

10. Wüst $\mathrm{S}$, Federenko I, Hellhammer $\mathrm{DH}$, Kirschbaum C. Genetic factors, perceived chronic stress, and the free cortisol re- sponse to awakening. Psychoneuroendocrinology. 2000 ;25 (7): 707- 720.

11. Karlson B, Eek F, Hansen ÅM, Garde AH, Ørbæk P. Cortisol variability and selfreports in the measurement of workrelated stress. Stress and Health. 2011;27:e11-e24.

12. Takai N, Yamaguchi M, Aragaki T, Eto K, Uchisashi K, Nishikawa Y. Effect of psychological stress on the salivary cortisol and amylase levels in healthy young adults. Arch Oral Biol. 2004;49 (12):963- 968.

13. Ghaddar A, Ronda E, Nolasco A, Álvares N, Mateo I. Exposure to psychosocial risks at work in prisons: does contact with inmates matter? A pilot study among prison workers in Spain. Stress and Health. 2011;27:1706.

14. Pérez-Ciordia I, Guillén F. Urgencias hospitalarias y extrahospitalarias en Navarra. Razones que las motivan. An Sist Sanit Navar. 2009;32: 371-384.

15. Sempere-Selva T, Peiró S, Sendra-Pina P, Martínez Espín C, López-Aguilera I. Inappropriate use of an accident and emergency department: magnitude, associated factors, and reasons- an approach with explicit criteria. Ann Emerg Med. 2001;37 (6):568-579.

16. Moncada Lluís S1, Llorens Serrano C, Font Corominas A, Galtés Camps A, Navarro Giné A. Psychosocial risk exposure among wage earning population in Spain (200405): reference values of the 21 dimensions of COPSOQ ISTAS21 questionnaire. Rev Esp Salud Pública. 2008;82 (6):667-675.

17. Fries E, Dettenborn L, Kirschbaum C. The cortisol awakening response (CAR): facts and future directions. Int J Psychophysiol. 2009; 72 (1): 67-73.

18. Karasek R. Job demands, job decision latitude and mental strain: implications for job re-design. Admins Sci Q. 1979;24:285-308.

19. Escribà-Agüir V, Martín-Baena D, PérezHoyos S. Psychosocial work environment and burnout among emergency medical and nursing staff. Int Arch Occup Environ Health. 2006;80 (2):127-133.

20. Karasek R, Theorell T. Healthy Work. Stress, productivity, and the reconstruc- 
tion of working life. Nueva York: Basic Books; 1990.

21. Fischer JE, Calame A, Dettling AC, Zeier H, Fanconi S. Objectifying psychomental stress in the workplace-an example. Int Arch Occup Environ Health. 2000;73:s4652.

22. Hanson EK, Maas CJ, Meijman TF, Godaert GL. Cortisol secretion throughtout the day, percpeptions of the work environment, and negative affect. Ann Behav Med. 2000;22 (4):316-324.

23. Hjortskov N, Garde AH, Orbaek P, Hansen AM. Evaluation of salivary cortisol as a biomarker of self-reported mental stress in field studies. Stress Health. 2004;20:91-8.

24. Weibel L, Gabrion I, Aussedat M, Kreutz G. Work-related stress in an emergency medical dispatch center. Ann Emerg Med. 2003;41 (4): 500-506.

25. Yang $Y$, Koh D, Ng V, Lee FC, Chan G, Doong F, Chia SE. Salivary cortisol levels and work-related stress among emergency department nurses. J Occup Environ Med. 2002;43 (12):1011-1008.

26. Hansen $A M$, Blangsted AK, Hansen EA, Sogaard K, Sjogaard G. Physical activity, job demand-control, perceived stressenergy, and salivary cortisol in white-collar workers. Int Arch Occup Environ Health. 2010;83 (2): 143-153.

27. Oldehinkel AJ, Ormel J, Bosch NM, Bouma EM, Van Roon AM, Rosmalen JG, Riese H. Stressed out? Associations between perceived and physiological stress responses in adolescents: The TRAILS study. Psychophysiology. 2011;48 (4):441-452.

28. Chida Y, Steptoe A. Cortisol awakening response and psychosocial factors: a systematic review and meta-analysis Biol Psychol. 2009;80 (3):265-278.

29. Eller NH, Kristiansen J, Hansen AM. Longterm effects of psychosocial factors of home and work on biomarkers of stress. Int J Psychophysiol. 2011;79 (2):195-202. 